\title{
Verzeichnis der Abkürzungen und Zeitschriften
}

\author{
$\mathrm{BGH} \quad$ Bundesgerichtshof \\ BGHZ Entscheidungen des Bundesgerichtshofs in Zivilsachen (Band und \\ Seite) \\ BT.-Drucksache Bundestagsdrucksache \\ BVerwGE Entscheidungen des Bundesverwaltungsgerichts (Band und Seite) \\ GRUR Gewerblicher Rechtsschutz und Urheberrecht, Zeitschrift der \\ Deutschen Vereinigung für gewerblichen Rechtsschutz und Ur- \\ heberrecht, Weinheim-Bergstraße \\ GRUR Ausl. GRUR Auslandsteil \\ h.A. herrschende Ansicht \\ InterGU Intemationale Gesellschaft fur Urheberrecht $\theta . V$. \\ KUG Gesetz betreffend das Urheberrecht an Werken der bildenden \\ Künste und der Photographie vom 9. Januar 1907, RGBI. 7, BGBI. \\ III 4 Nr. 440-3 \\ LUG Gesetz betreffend das Urheberrecht an Werken der Literatur und \\ der Tonkunst vom 19. Juni 1901, RGBI. 227, BGBI. III 4 Nr. 440-1 \\ Melos Zeitschrift für neue Musik, Mainz \\ Mitteilungen Schweizerische Mitteilungen über gewerblichen Rechtsschutz und \\ Urheberrecht, Zürich \\ NJW Neue Juristische Wochenschrift, München und Frankfurt/Main \\ OLG Oberlandesgericht (mit Ortsnamen) \\ OLGZ Schulze OLGZ = Rechtsprechung der Oberlandesgerichte zum \\ Urheberrecht \\ OVG Oberverwaltungsgericht \\ PatG Patentgesetz \\ RG Reichsgericht \\ RGZ Entscheidungen des Reichsgerichts in Zivilsachen \\ RGSt Entscheidungen des Reichsgerichts in Strafsachen \\ UFITA Archiv für Urheber-, Film- Funk- und Theaterrecht, Baden-Baden \\ UG Gesetz über Urheberrecht und verwandte Schutzrechte vom \\ 9. September 1965 BGBI. I S. 1273
}





\section{Prof. Dr. Benvenuto Samson}

gewidmet

Vielerlei Hinweise, Anregungen und Gesprăche haben meine Arbeit gefordert. Ich danke dafür den Herren Prof. Dr. B. Samson (Frankfurt am Main), Prof. Dr. M. Rehbinder und Dr. W. Larese (Zürich), Prof. Dr. L. Finscher (Frankfurt am Main), G. M. Koenig und W. Kaegi (Institut für Sonologie, Utrecht), K. H. Stockhausen (Köln), Dr. W. Brennecke (WDR Köln) und Dr. W. Vogelsang (Polydor International, Hamburg). 
